of the scapula with feeble breath-sounds and a few soft râles. In the supra-spinous fossa there was cavernous breathing with whispering pectoriloquy. There was no indication of mischief on the left side. The patient had tuberculous disease of the spine in a progressive condition, for which he was wearing a poroplastic jacket. His urine contained a trace of albumin, but no casts were found. His temperature during the first five days was $100^{\circ} \mathrm{F}$. at night, but on the following three days was only once above $99^{\circ}$ The "Tuberculin $R$ " treatment was commenced on Sept. 9th. The patient was kept in bed, strict antiseptic precautions were observed, and the temperature was taken every four hours night and day. The following is a list of the injections given :-

No. Date.

$$
\begin{aligned}
& 1 \text {... Sept. } \\
& \text {... } 5 \text { क } 5 \text { mg. in } 5 \text { c.c. }
\end{aligned}
$$

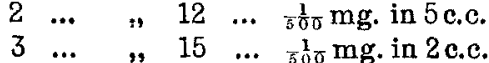

$$
\begin{aligned}
& 4 \ldots \quad 16 \quad 19,190 \\
& 4 \text { … } \\
& \frac{1}{6} \mathrm{mg} \text {. in } 4 \text { c.c. } \\
& \text { Tूर } \mathrm{mg} \text {, in } 5 \mathrm{c.c} \\
& \frac{1}{50} \mathrm{mg} \text {. in } 2 \mathrm{c.c} \\
& 1 \mathrm{mg} \text {. in } 1 \text { c.c. } \\
& 2 \mathrm{mg} \text {. in } 2 \mathrm{ec} \text {. } \\
& 3 \mathrm{mg} \text {, in } 3 \text { c.c. } \\
& 3 \mathrm{mg} \text {. in } 3 \text { c.c. } \\
& 3 \mathrm{mg} \text {. in } 3 \mathrm{c} \mathrm{c} \\
& 3 \frac{1}{2} \mathrm{mg} \text {. in } 3 \frac{1}{2} \mathrm{c} \text {. } \\
& 4 \mathrm{mg} \text {. in } 4 \text { c.c. } \\
& 4 \mathrm{mg} \text { in } 4 \text { c.c. } \\
& 4 \mathrm{mg} \text {. in } 4 \mathrm{c} \mathrm{c} \\
& 3 \mathrm{mg} \text {. in } 3 \mathrm{c.c} \text {. } \\
& 4 \mathrm{mg} \text {. in } 4 \mathrm{c.c} \\
& 4 \mathrm{mg} \text {. in } 4 \mathrm{c} \mathrm{c} \\
& 5 \mathrm{mg} \text {. in } 5 \mathrm{c.c} \\
& 2 \mathrm{mg} \text {. in } 2 \text { c.c. }
\end{aligned}
$$
$100 \cdot 8^{\circ} \mathrm{F}$.

None.

$98.0^{\circ}$ to $100.0^{\circ}$ in $7 \frac{1}{2}$ hours. None.

None.

$98.0^{\circ}$ to $99.8^{\circ}$ in 8 hours. $98 \cdot 6^{\circ}$ to $100 \cdot 2^{\circ}$

$99.0^{\circ}$ to $101.2^{\circ}$ in 20 hours. $99.2^{\circ}$ to $101.8^{\circ}$ in 12 hours $99.0^{\circ}$ to $101 \cdot 6^{\circ}$ in 24 hours $99 \cdot 4^{\circ}$ to $1014^{\circ}$ in 16 hours. $992^{\circ}$ to $1004^{\circ}$ in 20 hours. $99 \cdot 2^{\circ}$ to $1010^{\circ}$ in 12 hours.

$980^{\circ}$ to $1018^{\circ}$ in 24 hours. $98 \cdot 0^{\circ}$ to $100 \cdot 0^{\circ}$

$99 \cdot 0^{\circ}$ to $100 \cdot 8^{\circ}$

$98 \cdot 0^{\circ}$ to $99 \cdot 6^{\circ}$

$98.0^{\circ}$ to $102 \cdot 4^{\circ}$. None. $100.4^{\circ}$ to $1016^{\circ}$ in 8 hours.

From this table it will be seen that in 12 weeks the patient had 20 injections in doses ranging from $\tau_{0} \frac{1}{0}$ th of a milligramme to five milligrammes. A detailed examination of the condition of the chest was made every week and there was no improvement in the physical signs, but, on the contrary, there was some extension of the mischief at the right apex. The tubercle bacilli were still found in abundance in the expectoration. The general symptoms showed no amelioration and for a considerable period the patient suffered from profuse night-sweats. The only hopeful sign was that the appetite was maintained and that the patient did not lose flesh. He was discharged on Dec. 10th.

C.LSE 2.-A man, aged 35 years, was admitted to Westminster Hospital on August 5tb, 1898. He was in the hospital for pleurisy with effusion on the right side in 1896. He remained well until Christmas, 1897, when be caught a bad cold and since then his cough had never left him. He had night-sweating and there was considerable loss of flesh. On admission the physical signs were impairment of movement at the right apex, dulness on percussion, bronchial breathing in the first and second intercostal spaces, accompanied by moist râles. Moist rầ'es were also heard at the right back up to the angle of the scapula. On the left side there was dulness at the base with moist sounds. Tubercle bacilli were found in abundance in the expectoration. The temperature for four weeks after admission, during which he had only symptomatic treatment, usually reached $103^{\circ} \mathrm{F}$. in the evening. On Sept 12th he was given a hypodermic injection of ${ }_{3}^{1} 0$ th of a milligramme of "tuberculin $\mathrm{R}$ " which produced no reaction. On the 14th the dose was repeated without effect and on the 16th it was increased to $\frac{1}{\frac{1}{5}} \mathrm{t}$ th of a milligramme. On the $22 \mathrm{nd}$ at $8 \mathrm{~A}$.M. when the temperature happened to be only $97.0^{\circ}$, he was given $-\frac{1}{2} \sigma^{2}$ th of a milligramme and the temperature rose to $99.8^{\circ}$, but whether as the result of the injection it was impossible to determine. On the 27th he was given one milligramme and on the 31st two milligrammes, and again without any posi tive influence on the temperature. There was no improvement in the physical signs and on Oct. 2nd he took his discharge, his condition being no better than on admission. He died three weeks after leaving the hospital and no postmortem examination was obtained.

CASE 3.-A man, aged 45 years, was admitted to Westminster Hospital on August 21st, 1897. He stated that he had had a cough since February, 1896, the cough being constant and accompanied by much expectoration. He had a bad attack of bæmoptysis five months before and since ther had frequently spat blood, the last time being about month before admission. $\mathrm{He}$ had been steadily losing flesh for over a year, but had not suffered from nightsweats. There was flattening with diminished movement at the right apex in front and the percussion note over the whole of the right side was impaired. At the right apex the breath-sounds were weak and were accompanied by numerous fine râles. In the outer half of the first two intercostal spaces whispering pectoriloquy was obtained. The temperature during the first week usually reached $102^{\circ} \mathrm{F}$. in the evening. On August 29 th at $11.55 \mathrm{~A} . \mathrm{M}$. the temperature being $98^{\circ}$, he was given a hypodermic injection of $5 \frac{1}{0} \mathrm{t}_{\mathrm{th}}$ of a milligramme of tuberculin $\mathrm{R}$. At noon the temperature was $98.8^{\circ}$, and at 1 P.M. $99.6^{\circ}$. It then fell again and at 3 P.M. was $98^{\circ}$. On Sept. 1st at 1.45 P.M. he was given an injection of $\frac{1}{2}{ }^{\frac{1}{5}}$ th of a milligramme and at 6 P.M. his temperature was $101 \cdot 6^{\circ}$. On the 3rd at 9.30 A.M., the temperature being $100^{\circ}$, he was given an injection of 10 th of a milligramme and, at $10 \mathrm{~A} . \mathrm{M}$. the temperature was $101 \cdot 8^{\circ}$, after which it gradually fell. On the 9 th at 6.15 P.M., the temperature being $100^{\circ}$, the patient was given a hypodermic injection of $\frac{1}{8} \mathrm{rd}$ of a milligramme. At 6.30 the temperature was $101^{\circ}$ and at 7 it was $101.8^{\circ}$, after which it gradually fell. The patient was given in all six injections, the maximum being $\frac{1}{5}$ th of a milligramme, but there was no improvement either in the symptoms or in the physical signs. His appetite failed to improve, and as he was rapidly losing flesh he was sent home

Remarks by Dr. MURRELL.-My experience of the treat ment of phthisis with tuberculin $\mathrm{R}$ has been so limited compared with that of Professor McCall Anderson that it is with some hesitation that I venture to call attention to these cases. My experience would probably have been larger had the results been more favourable. It may be that if cases were carefully selected and only patients in a very early stage treated by this method better results would be secured. Possibly, too, the number of injections was too small, for I believe that in a successful case published by Professor McCall Anderson 47 injections were given in four months. The maximum dose of the new tuberculin is said to be 20 milligrammes, but that is a very large quantity and I have not ventured beyond five milligrammes. The irritation produced at the seat of infection is often a source of trouble and inconvenience to the patient. The expense is a serious consideration and in hospital practice a physician hesitates to recommend his house committee to sanction the employment of a remedy which runs up to $17 \mathrm{~s}$. a dose. I endeavoured to get it made in England on more reasonable terms, but was told that although the formula was published the exact details were not known. I have no wish to speak unfavourably of tuberculin $R$ and my limited experience would not justify me in doing so, but I am positive that in these particular cases I could have obtained far better results with the formic aldehyde treatment, the details of which I have already published.

\section{MORPETH COTTAGE HOSPITAL.}

A CASE OF FRACTURE OF THE LEFT SIDE OF THE SKULL WITH COMPLETE RIGHT HEMIPLEGIA ; OPERATION ; RECOVERY.

(Under the care of Dr. E. F. L. DE JERSEY.)

IN all cases of depressed fracture of the skull, except in those in young children, it is now the accepted treatment to trephine at once, even in the absence of symptoms and even if the fracture be unaccompanied by a lesion of the scalp. In the following case the coma and the right-sided hemiplegia pointed clearly to the lesion on the left motor area, and the fact that pressure cver the fracture produced spasm of the right side of the body confirmed the diagnosis. The harmlessness and the value of modern treatment of even extensive fractures of the skull could not be better illustrated than in the case recorded below.

A man, aged 45 years, was admitted into the Morpeth Cottage Hospital on Feb. 22nd, 1900, having been struck on the left side of the head on the 17 th with a pole six feet in length and from six to nine inches in diameter. There was complete unconsciousness with right-sided hemiplegia and retention of urine and fæces. The temperature was $102^{\circ} \mathrm{F}$ On the day before the patient's admission into the bospital (Feb. 21st) slight crepitation was detected over the left parietal bone at about its centre. There was no external wound or discolouration over the site of the injury, only slight 
pitting on pressure. There was slight effusion of blood a little above and in front of the left ear. There were also two black eyes produced by fist-blows. On firm pressure over the site of the fracture spasm of the whole right side of the face and body was produced.

An operation was performed at 3.30 P.M. on Feb. 22nd. An incision was made from a point one inch above the left frontal eminence of the frontal bone and three and threequarter inches above the left external canthus down to a point half an inch above the lower border of the left parietal bone and two and a half inches above the left external auditory meatus up to a point a little above and behind the left parietal eminence four and a half inches above the left mastoid process and five and a half inches from the startingpoint. On raising the flap thus formed an extensive stellate, depressed, fissured, and comminuted fracture was found, the stellate and comminuted portion being situated immediately in front of the left parietal eminence. On raising the depressed and comminuted fragments both the internal and external tables of bone were found to be involved, fragments of bone projecting in all directions into the brain substance, tearing to shreds the dura mater, the arachnoid, and the pia mater lying over the convolutions of the brain. After the removal of the fragments of bone an area of brain two and a half inches by three-quarters of an inch was exposed. From the anterior border of this area in the bone was a fissure extending downwards and forwards into the frontal bone towards the outer border of the left orbit; ancther fissure extended from the posterior part through the remaining portion of the parietal bone into the occipital bone. This latter fissure was much wider than the anterior one, it being about a quarter of an inch in breadth. Beneath the stellate and comminuted fracture was a large hæmatoma, which was left undisturbed. At a point four inches at right-angles to Reid's line and two inches behind the exterior auditory meatus, being at a point a little posterior to the left parietal eminence, was a cavity extending right into the substance of the brain large enough to admit the little finger quite easily. This cavity corresponded to the upper end of the left Rolandic fissure, thereby involving the upper ends of the left ascending frontal and parietal convolutions, the latter chiefly. This cavity, no doubt, was produced by the injury, but degenerative changes had already set in, as the brain matter round the orifice was quite pulpy and friable. The fracture covered most of the motor area, there being complete right-sided hemiplegia and motor aphasia, showing that the left inferior frontal convolution must have been damaged as well as the parietal convolutions. Some of the difficulty in speech was due to paralysis of the tongue, but after the latter had passed away there was considerable aphasia left. The patient stated when he got the use of his tongue that he could hear everything which was said to him and wished to answer but he could not get his words out. Part of the whole thickness of the parietal bone was replaced, a gauze plug was inserted into the cavity in the brain and brought out under the flap, which was sutured, and a dry dressing was put on. The plug was removed on March 3rd and the wound healed without suppuration.

Before operation the pulse was 40 , the breathing was very quiet, almost inaudible, and deep coma was setting in. At 9 P.M. on the evening of the operation the patient was still unconscious but he raised his right leg every now and again. The pulse was quicker and the breathing was stronger. The temperature was $97 \cdot 5^{\circ}$. He had taken nourishment, and this he had not done before since the injury. He was very restless and kept on raising himself from the pillow. Shoulder bands were put on which kept him still, they being tied to the head of the bed. On Fieb. 23rd (the day following the operation) the patient had had a pretty good night though he had been very restless at times. He had said the word "No" and had made signs for a drink. The urine and fæces were passed involuntarily. The temperature was $98 \cdot 2^{\circ}$

From the operation the patient steadily improved and never once did the temperature rise above the normal. On Feb. 24th the right arm could be raised slightly. On the 25th the right arm could be moved freely and consciousness was returning. On the 28th the patient tried hard to speak but could not get the words out. He opened his mouth when asked to do so and said small words like "Yes" and "No," but usually be used the latter to questions which were put to him. Consciousness had almost completely returned. On March 7th the patient put out his tongue for the first time.
It deviated much to the right. He carried on a little disconnected conversation, there being much motor aphasia. He started taking light solids on this day. On the 12th he gave a statement to the police as to the cause of his injury quite rationally, but with difficulty at times owing to the aphasia. He said that he had a bad memory and could not remember names so well as he could before the injury. On the 16 th the patient got up. On April 2nd he walked about the ward quite well and was able to carry on a conversation with very little difficulty. The paralysis had com. pletely disappeared, but there was slight weakness of the right side, specially noticeable by the clench of the two hands. On the 10th the patient was dismissed from the hospital.

Hemarks by Dr. DE JERSEY.-The order in which the paralysis disappeared was very prominent. Almost directly after the pressure over the motor area had been relieved movement of the paralysed side returned, starting with the leg, then followed by the upper extremity, the face, and lastly by the tongue. The shoulder movements returned before those of the elbow, and those of the elbow before those of the hand-viz., the finer movements. The upper face being only slightly affected returned to its normal state long before the lower face. The return of the paralysed side to normal brought out very well the fact that the parts which rarely act independently of their fellows on the opposite side are the parts that are usually the least paralysed and consequently are the parts that recover the most quickly.

Before the operation there was retention of urine; after operation there was retention with at times incontinence, the bladder being frequently found above the pubes. The urine was drawn off for five days and the bladder was washed out with a weak solution of boric acid, as there was slight cystitis. Fæces were passed involuntarily for two or three days after the operation; after that there was constipation.

The interesting points in the case are the rapid recovery after the pressure on the brain had been relieved, the signs of relieved pressure appearing before those of shock began to pass off, and consciousness returning comparatively late.

The cavity found at the top of the motor area seemingly has left no bad effects, as also the gaping fissures in the bone extending into the frontal and occipital areas respectively. The fissures were left as approximation of the two sides could not be obtained, although seemingly all wedges of bone likely to cause the gaping were removed. It was thought unwise to make further flaps to discover actually how far these fissures extended, as in all probability no harm would be done by leaving them. This was the case. Another interesting point is the fact that a piece of bone, including both the external and internal table, completely deprived of its periosteum, was replaced and has become firmly adherent to the adjacent bone. Its size was nearly balf an inch square.

\section{attedical Soctietics.}

\section{OBSTETRICAL SOCIETY OF LONDON,}

Porro-Cesarean Hysterectomy with Retro-peritoncal Treat ment of the Stump in a Case of Fibroids Obstructing Labour, with Remarks upon the Relative Advantages of the "Modern Porro" Optration over the Sänger-Casarcan in most other Cases requiring Abdominal Section.

A MEETING of this society was held on July 5th at 20, Hanover-square, W., Mr. AlbaN Doran, the President, being in the chair.

Dr. AMAND ROUTH read a paper on Porro-Cæsarean Hysterectomy with Retro-peritoneal Treatment of the Stump in a Case of Fibroids Obstructing Labour, with Remark upon the Relative Advantages of the "Modern Porro" Operation over the Sänger-Cæsarean in most other Cases requiring Abdominal Section. When the patient was first seen the pelvis was occupied by a large fibroid and the cervix uteri was out of reach above the symphysis. During the thirtyfourth week the pelvic fibroid was rather suddenly drawn up out of the true pelvis and it was hoped that parturition would be naturally performed. As it was found that the head was arrested just above the lower segment of the uterus by two opposing fibroids a Porro-Crsarean operation was 